\title{
O QUE OS ALUNOS PENSAM SOBRE SUAS AVALIAÇÕES? CLASSIFICAÇÃO DAS OPINIÕES EXPRESSAS NAS QUESTÕES ABERTAS DA CPA
}

CURITIBA/PR MAIO/2018

\author{
Tania Frugiuele Soares Agostinho - UNINTER - tania.a@uninter.com \\ Lucas Massimo Tonial Antunes de Souza - UNINTER - lucas.so@uninter.com \\ Débora Cristina Veneral - UNINTER - debora.v@uninter.com
}

Tipo: Relato de Experiência Inovadora (EI)

Categoria: Métodos e Tecnologias

Setor Educacional: EDUCAÇÃO SUPERIOR

\begin{abstract}
RESUMO
O trabalho discute os conteúdos das opiniões dos estudantes nas questões abertas da Comissão Própria de Avaliação. As opiniões dos estudantes acerca das avaliações em seis cursos de graduação foram classificadas em oito categorias. Os resultados indicam que há uma diversidade de opiniões conforme cada curso. As implicações desse estudo apontam para o aperfeiçoamento da tomada de decisões pelos gestores das IES, visto que, devido às características dessas plataformas, permitem que sejam realizadas consultas periódicas para mensurar tendências e regularidades nas opiniões expressas de modo espontâneo acerca das rotinas do EAD.
\end{abstract}

Palavras-chave: CPA; sistema de avaliação; opinião dos alunos.

AGRADECIMENTOS

AGRADECEMOS AOS PESQUISAdORES RESPONSÁVEIS PELA REALIZAÇÃO dOS QUESTIONÁRIOS DA COMISSÃO PRÓPRIA DE AVALIAÇÃO, SEM OS QUAIS ESSA PESQUISA NÃO TERIA SIDO POSSÍVEL 


\section{Introdução}

Este breve artigo pretende abordar a importância da Comissão Própria de Avaliação (CPA) para as Instituições de Ensino Superior (IES) que ofertam cursos a distância e como os resultados aferidos podem auxiliar, não só, as coordenações dos cursos e tutorias a aperfeiçoarem seus conteúdos e atendimento aos alunos, como também, os setores responsáveis pela elaboração das questões disponibilizadas nas variadas atividades avaliativas ofertadas aos alunos.

Para demonstrar como essa ferramenta pode ser valiosa para a melhoria da qualidade dos processos avaliativos dos cursos ofertadas em EAD, este trabalho abordará os resultados obtidos em uma determinada CPA, aplicada em período específico e referente a cursos pertencentes a uma das Escolas que compõem uma grande instituição de ensino a distância do Brasil.

Trata-se da pesquisa da CPA aplicada em dois momentos, uma no período de 28 de outubro a 15 de novembro (fase 1) e outra no período de 02 a 17 de dezembro de 2017, que abrange a oferta de 01 Unidade Temática de Aprendizagem (UTA), dividida em dois ciclos compostos por 02 disciplinas cada uma e que apresentam conteúdos interrelacionados e dispostos de maneira a formar uma Unidade Temática de Aprendizagem. Os dados que discutiremos nesse trabalho referem-se às percepções de estudantes de dois cursos de graduação na modalidade bacharelado e de quatro cursos de graduação na modalidade tecnologia.

Portanto, o objetivo geral desse trabalho é discutir as percepções de estudantes de graduação acerca do sistema de avaliações empregados em cursos de graduação no ensino superior. Na primeira seção do trabalho justificamos a importância de um levantamento de dados dessa natureza, no segundo item apresentaremos com mais pormenores como foi realizada a classificação das opiniões dos estudantes, e na terceira parte desse trabalho apresentaremos os resultados encontrados em cada um dos quatro cursos.

\section{Justificativa e referencial teórico: a percepção dos estudantes e a gestão do} EAD

A proposta presente nesse trabalho parte de algumas premissas que devem ser contextualizadas. A realização de consultas periódicas com os estudantes é um importante mecanismo para consolidar protocolos de auto avaliação e monitoramento do processo de ensino no âmbito das Instituições de Ensino Superior (IES). De acordo com 
Sanchez, Sanchez e Albertin "Gestores têm enfrentado a necessidade de decidir sobre como otimizar as novas oportunidades de produção de ofertas educacionais com os variados níveis de autonomia que o Ensino a Distância (EaD) permite" (SANCHEZ et al. 2015, p.512). Entre essas novas oportunidades é possível incluir a consulta com os estudantes acerca do modo como eles estão sendo avaliados ao longo de suas disciplinas, utilizando para essa consulta os meios disponíveis nas mesmas plataformas em que ocorre o EAD.

Com a difusão de novas tecnologias de informação, "observamos com mais atenção as relações entre conhecimento, tecnologia e ensino-aprendizagem (...) Torna-se, assim, um grande desafio para os educadores perceberem que as relações que se conectam à aprendizagem transcendem as salas de aula convencionais e se aproximam, cada vez mais, das experiências individuais vividas na diversidade das linguagens tecnológicas, e também daquilo que chamamos de grupos sociais" (França 2009, p.56).

Nesse contexto, a avaliação dos próprios alunos é uma informação estratégica. Ao tomar como base as percepções dos estudantes para monitorar a qualidade do EAD os gestores das IES podem dar um passo importante para a oferta de um ensino em que os indivíduos sintam-se de fato sujeitos de seu processo de aprendizagem. Isso é tanto mais importante à medida em que "estamos assistindo ao nascimento de uma geração de jovens inovadores, antenados, entendedores do poder da mídia, que aprendem por meio da interação. A informação não é apenas consumida. Ela também é produzida pelos jovens. [...] Esses jovens têm autoconfiança e autoestima. Sabem que seu futuro não está nas mãos de governos ou empresas. Valorizam os direitos individuais, como a privacidade e a liberdade de expressão. E mais: querem ser tratados com justiça." (Bohadana \& Valle 2009, p.563).

Assim, a principal justificativa teórica para um estudo como esse é abandonar a perspectiva de um estudante passivo, que não participa do processo de ensino. O nosso estudo se posiciona em convergência com a proposta de Marchisotti, Oliveira e Lukosevicius, em examinar a representação social da educação a distância. Segundo esses autores "A educação a distância é baseada na iniciativa do aluno, usando suas habilidades para interagir e resolver problemas em grupos e não permite a simples memorização de conteúdo. Em outras palavras, aprender baseado em "saber fazer algo" e não apenas "conhecer fatos", que só ocorre quando se quebra o modelo tradicional de ensino". (Marchisotti et al. 2017, p.744, tradução livre)

Mas além dessa justificativa teórica, um estudo como o nosso serve para apontar a importância de indicadores objetivos obtidos com base em questionários como os 
elaborados na Comissão Própria de Avaliação (CPA). Trata-se de mobilizar não apenas a infraestrutura do Ambiente Virtual de Aprendizagem (que permite a consulta com todos os estudantes vinculados aos cursos), mas sobretudo, trata-se de formalizar nessas plataformas eletrônicas protocolos de consulta com os alunos, construindo bases de dados coletadas de modo sistemático, que permitam, através de indicadores mensuráveis, o aperfeiçoamento do sistema de avaliação. Assim, "do ponto de vista dos gestores de instituições de ensino, o desenvolvimento dessa modalidade torna-se, portanto, uma decisão de busca pela eficiência. Usar recursos adequadamente para maximizar o atendimento aos objetivos consiste em identificar quais os meios mais adequados para veicular os materiais, de acordo com o perfil dos alunos."(SANCHEZ et al. 2015, p.524).

\section{Discussão metodológica: a classificação dos comentários realizados nas questões abertas da CPA.}

Os questionários realizados pela CPA são formados por questões fechadas e por questões abertas. O preenchimento dos questionários é facultativo, e esse é um aspecto muito importante para a análise dos dados que foram compilados nesse trabalho, a saber, o caráter espontâneo da manifestação discente. Ao nosso entender, ao expor suas opiniões acerca de como são realizadas as avaliações, essa disposição dos estudantes supõe pelo menos a dedicação de alguns minutos para apresentar quais são os pontos que ganham destaque na sua percepção. Esse empenho em se manifestar acerca de um ponto importante para o processo de aprendizagem (o sistema de avaliação) pode ser interpretado como uma tentativa de influenciar o processo de ensino, e de se fazer presente como um sujeito ativo sobre a sua própria formação.

Os questionários ficam disponíveis para os estudantes por cerca de duas semanas, e o preenchimento não é obrigatório. Portanto, por se tratar de uma amostra intencional, as opiniões desses discentes não permitem extrapolar conclusões para a população de alunos de cada curso - esse é o motivo pelo qual o nome dos cursos será suprimido. Os dados analisados são todos agregados, e não há nenhuma referência direta ao que foi escrito pelo próprio estudante. Esperamos com isso preservar a condição de anonimato dos informantes durante as fases de coleta e tratamento dos dados.

Esses esclarecimentos são importantes para caracterizar de modo adequado a amostra que embasou a realização desse estudo. O mesmo estudante pode apresentar opiniões sobre diferentes aspectos do sistema de avaliação, e o universo com o qual trabalharemos refere-se ao total de opiniões, portanto, o total de opiniões não se refere ao total de respondentes. 
O objetivo do estudo é captar tendências e regularidades nessas opiniões manifestas de modo espontâneo. Para essa finalidade as opiniões expressas pelos respondentes foram agregadas em oito categorias, que são descritas no Quadro 1 a seguir:

Quadro 1 - Descrição detalhada das categorias utilizadas na classificação dos comentários realizados nas questões abertas

\begin{tabular}{|c|c|}
\hline Categoria & Descrição \\
\hline \multicolumn{2}{|l|}{ 2. Observações sobre conteúdo das questões } \\
\hline & $\begin{array}{l}\text { Inclui relatos sobre dificuldade em encontrar as respostas, descompasso com a sequência das rotas } \\
\text { ou divergência entre conteúdo cobrado na avaliação e o que foi disponibilizado no material didático }\end{array}$ \\
\hline 3. Críticas ao sistema de avaliações & $\begin{array}{l}\text { Inclui pedidos para ampliar o número de questões na APOL, ou a quantidade de APOLS por fase, } \\
\text { inserir questões discursivas nas APOLS, igualar o peso das provas na composição da média e até } \\
\text { mesmo extinguir a prova discursiva. }\end{array}$ \\
\hline 4. Grau de complexidade das questões & $\begin{array}{l}\text { Inclui observações sobre dificuldade em entender aos enunciados das questões, dificuldade de } \\
\text { compreensão dos comandos e reprodução literal dos conteúdos dos materiais didáticos, como livros } \\
\text { e rotas de aprendizagem }\end{array}$ \\
\hline 5. Tempo nas discursivas & $\begin{array}{l}\text { Inclui pedidos de mais exercícios de fixação, ou realizar simulados antes das provas, sem efeito sobre } \\
\text { a média das disciplinas }\end{array}$ \\
\hline \multicolumn{2}{|l|}{ 7. Desconforto com erros de composição das provas } \\
\hline & $\begin{array}{l}\text { Inclui reclamações sobre questões repetidas, alternativas dúbias, distratores repetidos, problemas de } \\
\text { digitação ou erros ortográficos que atrapalham a interpretação do texto durante a avaliação. }\end{array}$ \\
\hline 8. Diversificar a base de elaboração das questões & $\begin{array}{l}\text { Inclui pedidos para abordar os assuntos das videoaulas nas provas, compor as avalições com } \\
\text { materiais das rotas (na mesma proporção em que se cobram conteúdos dos livros) e incluir questões } \\
\text { das APOLS nas provas. }\end{array}$ \\
\hline
\end{tabular}

I. APOL é a sigla de Atividade Pedagógica Online, uma avaliação de processo de aprendizagem, realizada sem supervisão, que fica disponível por quinze dias para os discentes.

Fonte: Elaboração própria, com base nos dados fornecidos pela Comissão Própria de Avaliação (CPA).

A classificação nessas categorias foi amparada por um princípio indutivo. Todos os comentários dos estudantes foram lidos pelos autores do trabalho, e quando as observações dos estudantes eram semelhantes, elas foram agregadas em cada uma das oito categorias descritas acima. Na próxima seção desse trabalho apresentaremos os resultados obtidos com a classificação de todas as opiniões nesses quatro critérios.

\section{Análise e discussão dos resultados: onde se concentram a maioria das opiniões que os estudantes emitem acerca do sistema de avaliação.}

O Gráfico 1 a seguir faz apresenta a distribuição de todas as 325 opiniões manifestadas pelos estudantes nas oito categorias 
Gráfico 1 - Classificação dos comentários realizados pelso alunos nas questões abertas relacionados às avaliações

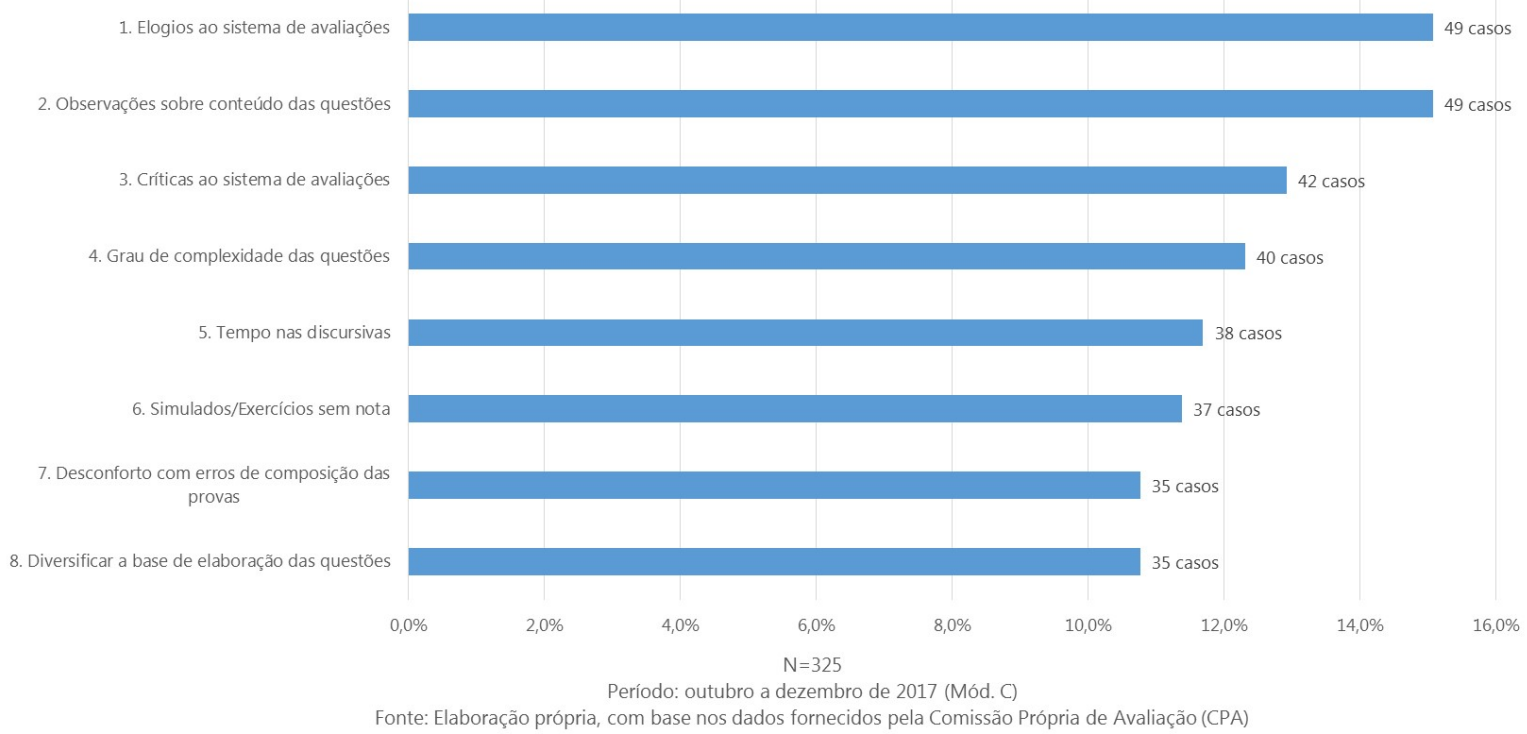

Os valores presentes no Gráfico 1 revelam que a maioria dos comentários são de elogios ao sistema de avaliações, ou sobre observações acerca do conteúdo das questões, seguidas das críticas ao sistema de avaliação. É oportuno para o nosso argumento essas três categorias tenham reunido 140 das 325 opiniões registradas nos questionários da CPA: isso revela a iniciativa dos estudantes em registrar uma opinião sobre como estão sendo obtidas suas notas, tal como foi esperado pelos autores do estudo.

A partir de agora vamos examinar como varia a percepção dos alunos conforme os cursos.

Tabela 1 - Estudantes do curso 1

\begin{tabular}{lccc}
\hline Categorias & Quantidade & Percentual & Percentual Acumulado \\
\hline Elogios ao sistema de avaliações & 6 & $17,6 \%$ & $17,6 \%$ \\
Críticas ao sistema de avaliações & 5 & $14,7 \%$ & $32,4 \%$ \\
Grau de complexidade das questões & 5 & $14,7 \%$ & $47,1 \%$ \\
\hline Desconforto com erros de composição das provas & 5 & $14,7 \%$ & $61,8 \%$ \\
Observações sobre conteúdo das questões & 4 & $11,8 \%$ & $73,5 \%$ \\
Tempo nas discursivas & 4 & $11,8 \%$ & $85,3 \%$ \\
Simulados/Exercícios sem nota & 3 & $8,8 \%$ & $94,1 \%$ \\
Diversificar a base de elaboração das questões & 2 & $5,9 \%$ & $100,0 \%$ \\
\hline Total & 34 & $100,0 \%$ & \\
\hline
\end{tabular}

Fonte: Elaboração própria, com base nos dados fornecidos pela Comissão Própria de Avaliação (CPA)

A tabela 1 revela que as categorias que reúnem os elogios e as críticas do ao sistema de avaliação reúnem $32,4 \%$ das 34 opiniões dos estudantes que pertencem ao curso 1 . O grau de complexidade das questões também foi mencionado em cinco das 34 opiniões de estudantes vinculados a esse curso. A categoria que menos foi acionada 
para classificar os estudantes desse curso é aquela que diz respeito à base de elaboração das questões. Isso sugere que, para os estudantes que quiseram manifestar suas opiniões, as avaliações nesse curso estão bastante diversificadas, vale dizer, são questões realizadas a partir do livro base, das videoaulas, dos materiais da rota de aprendizagem, etc.

Tabela 2 - Estudantes do curso 2

\begin{tabular}{lccc}
\hline Categorias & Quantidade & Percentual & Percentual Acumulado \\
\hline Observações sobre conteúdo das questões & 11 & $19,3 \%$ & $19,3 \%$ \\
Desconforto com erros de composição das provas & 11 & $19,3 \%$ & $38,6 \%$ \\
Diversificar a base de elaboração das questões & 9 & $15,8 \%$ & $54,4 \%$ \\
\hline Críticas ao sistema de avaliações & 8 & $14,0 \%$ & $68,4 \%$ \\
Grau de complexidade das questões & 7 & $12,3 \%$ & $80,7 \%$ \\
Elogios ao sistema de avaliações & 4 & $7,0 \%$ & $87,7 \%$ \\
Simulados/Exercícios sem nota & 4 & $7,0 \%$ & $94,7 \%$ \\
Tempo nas discursivas & 3 & $5,3 \%$ & $100,0 \%$ \\
\hline Total & 57 & $100,0 \%$ & \\
\hline
\end{tabular}

Fonte: Elaboração própria, com base nos dados fornecidos pela Comissão Própria de Avaliação (CPA).

$\mathrm{Na}$ tabela 2 vemos que, no curso 2, as categorias que agregam metade das opiniões são as observações sobre o conteúdo, o desconforto causado pelo erro na composição das questões, e de modo diverso aos estudantes do curso 1, aqui há 9 em 57 opiniões relacionadas à base de elaboração das questões das avaliações. O tempo destinado para as avaliações discursivas foi a categoria menos acionada ao classificar as opiniões dos estudantes.

Tabela 3 - Estudantes do curso 3

\begin{tabular}{lccc}
\hline Categorias & Quantidade & Percentual & Percentual Acumulado \\
\hline Simulados/Exercícios sem nota & 12 & $18,5 \%$ & $18,5 \%$ \\
Tempo nas discursivas & 11 & $16,9 \%$ & $35,4 \%$ \\
Diversificar a base de elaboração das questões & 11 & $16,9 \%$ & $52,3 \%$ \\
\hline Críticas ao sistema de avaliações & 9 & $13,8 \%$ & $66,2 \%$ \\
Grau de complexidade das questões & 9 & $13,8 \%$ & $80,0 \%$ \\
Desconforto com erros de composição das provas & 6 & $9,2 \%$ & $89,2 \%$ \\
Elogios ao sistema de avaliações & 5 & $7,7 \%$ & $96,9 \%$ \\
Observações sobre conteúdo das questões & 2 & $3,1 \%$ & $100,0 \%$ \\
\hline Total & 65 & $100,0 \%$ & \\
\hline Fonte: Elaboração própria, com base nos dados fornecidos pela Comissão Própria de Avaliação (CPA).
\end{tabular}

A tabela 3 indica que a realização de exercícios sem relação direta com a composição das médias, como simulados ou outras avaliações sem notas, é o que mais se destaca nas opiniões dos estudantes desse curso. Aqui as opiniões relacionadas ao tempo destinado para as avaliações discursivas também ganham destaque, são 11 em 65 opiniões. As observações sobre o conteúdo das questões foi a categoria menos acionada para classificar as opiniões dos estudantes desse curso. 
Tabela 4 - Estudantes do curso 4

\begin{tabular}{lccc}
\hline Categorias & Quantidade & Percentual & Percentual Acumulado \\
\hline Observações sobre conteúdo das questões & 20 & $29,0 \%$ & $29,0 \%$ \\
Tempo nas discursivas & 16 & $23,2 \%$ & $52,2 \%$ \\
\hline Grau de complexidade das questões & 10 & $14,5 \%$ & $66,7 \%$ \\
Elogios ao sistema de avaliações & 6 & $8,7 \%$ & $75,4 \%$ \\
Desconforto com erros de composição das provas & 6 & $8,7 \%$ & $84,1 \%$ \\
Críticas ao sistema de avaliações & 5 & $7,2 \%$ & $91,3 \%$ \\
Simulados/Exercícios sem nota & 5 & $7,2 \%$ & $98,6 \%$ \\
Diversificar a base de elaboração das questões & 1 & $1,4 \%$ & $100,0 \%$ \\
\hline Total & 69 & $100,0 \%$ \\
\hline \multicolumn{7}{r}{ Fonte: Elaboração própria, com base nos dados fornecidos pela Comissão Própria de Avaliação (CPA). }
\end{tabular}

$\mathrm{Na}$ tabela 4 vemos que apenas duas categorias reúnem mais da metade das opiniões desses estudantes: são 20 manifestações relacionadas ao conteúdo das provas, e 16 opiniões acerca do tempo destinado para a realização das provas discursivas. Tal como se observa na Tabela 3, também entre os estudantes do curso 4 a categoria menos acionada (apenas um caso) refere-se à diversificação dos tipos de conteúdo empregados nas avaliações.

Tabela 5 - Estudantes do curso 5

\begin{tabular}{lccc}
\hline Categorias & Quantidade & Percentual & Percentual Acumulado \\
\hline Elogios ao sistema de avaliações & 5 & $26,3 \%$ & $26,3 \%$ \\
Observações sobre conteúdo das questões & 3 & $15,8 \%$ & $42,1 \%$ \\
\hline Críticas ao sistema de avaliações & 3 & $15,8 \%$ & $57,9 \%$ \\
Grau de complexidade das questões & 3 & $15,8 \%$ & $73,7 \%$ \\
Tempo nas discursivas & 2 & $10,5 \%$ & $84,2 \%$ \\
Diversificar a base de elaboração das questões & 2 & $10,5 \%$ & $94,7 \%$ \\
Simulados/Exercícios sem nota & 1 & $5,3 \%$ & $100,0 \%$ \\
Desconforto com erros de composição das provas & 0 & - & \\
\hline Total & 19 & $100,0 \%$ & \\
\hline Fon
\end{tabular}

Fonte: Elaboração própria, com base nos dados fornecidos pela Comissão Própria de Avaliação (CPA).

A Tabela 5 indica que os estudantes do curso 5 são os que menos se manifestaram nos questionários da CPA analisados nesse trabalho, são apenas 19 opiniões registradas espontaneamente pelos alunos desse curso. Nota-se que a maior parte dessas opiniões registram elogios à como foram feitas, muito embora, devido ao seu número mais reduzido, todas as opiniões ficam bem distribuídas nas oito categorias. 
Tabela 6 - Estudantes do curso 6

\begin{tabular}{lccc}
\hline Categorias & Quantidade & Percentual & Percentual Acumulado \\
\hline Elogios ao sistema de avaliações & 23 & $28,4 \%$ & $28,4 \%$ \\
Críticas ao sistema de avaliações & 12 & $14,8 \%$ & $43,2 \%$ \\
\hline Simulados/Exercícios sem nota & 12 & $14,8 \%$ & $58,0 \%$ \\
Diversificar a base de elaboração das questões & 10 & $12,3 \%$ & $70,4 \%$ \\
Observações sobre conteúdo das questões & 9 & $11,1 \%$ & $81,5 \%$ \\
Desconforto com erros de composição das provas & 7 & $8,6 \%$ & $90,1 \%$ \\
Grau de complexidade das questões & 6 & $7,4 \%$ & $97,5 \%$ \\
Tempo nas discursivas & 2 & $2,5 \%$ & $100,0 \%$ \\
\hline Total & 81 & $100,0 \%$ & \\
\hline
\end{tabular}

Fonte: Elaboração própria, com base nos dados fornecidos pela Comissão Própria de Avaliação (CPA).

Os dados da Tabela 6 revelam que os estudantes do curso 6 são os que mais manifestaram opiniões nas questões abertas da CPA, são 81 manifestações, em que os elogios e as críticas reúnem pouco mais de $40 \%$ de todas as opiniões. A maior parte é de comentários favoráveis $(28,4 \%)$ e a categoria que agregou a menor quantidade de observações trata do tempo para a realização de avaliações discursivas, que só apareceu em duas opiniões.

\section{Considerações finais}

Os dados compilados para esse trabalho revelam que o trabalho da Comissão Própria de Avaliação (CPA) pode fornecer um insumo muito importante para a tomada de decisões estratégicas pelos gestores do EAD. Graças aos recursos disponíveis nas plataformas em que ocorre o EAD é possível realizar consultas periódicas com os estudantes.

O exercício proposto nesse trabalho tem a pretensão de apresentar os resultados e refletir sobre a relevância dessas consultas. Por meio delas é possível integrar a perspectiva dos discentes com a tomada de decisões tomadas na administração de cursos de graduação ofertados na modalidade EAD. A manifestação dos estudantes é uma oportunidade para que as equipes responsáveis pelos cursos, sejam os agentes que se ocupam da gestão escolar (tutores e coordenadores) sejam os profissionais que diretamente vinculados à produção dos conteúdos (autores e professores), uns e outros insiram a consulta com os alunos como parte da sua atividade laboral. A mensuração realizada com base em indicadores objetivos, elaborados com base em critérios comparáveis ao longo do tempo pode ser utilizada para valorizar o ponto de vista dos estudantes que manifestam suas opiniões de modo espontâneo, acerca de temas que Ihe são caros, como o sistema de avaliações, ou o método como são compostas suas médias. Os temas enfatizados a partir dessa consulta podem variar, ou ainda, as categorias com as quais trabalhamos podem ser aperfeiçoadas. Em qualquer caso, as opiniões emanadas pelo conjunto de estudantes são informações relevantes para 
incrementar a qualidade do EAD no Brasil.

Os indicadores extraídos desses questionários podem auxiliar a detectar o que aparece com mais ou com menos frequência nas opiniões dos estudantes. Esse tipo de informação pode ser utilizado para valorizar a percepção subjetiva dos discentes, e se levantamentos dessa natureza forem realizados de modo regular, é possível incrementar a tomada de decisão pelos gestores da IES, que pode ser realizada de modo sensível à opinião dos estudantes que escolhem se manifestar nos questionários da CPA.

\section{Referências bibliográficas}

Bohadana, E. \& Valle, L. do, 2009. O quem da educação a distância. Revista Brasileira de Educação, 14(42), pp.551-564.

França, G., 2009. Os ambientes de aprendizagem na época da hipermídia e da Educação a Distância. Perspectivas em Ciência da Informação, 14(1), pp.55-65.

Marchisotti, G.G., Oliveira, F.B. de \& Lukosevicius, A.P., 2017. The social representation of distance education from a Brazilian perspective. Ensaio: Avaliação e Políticas Públicas em Educação, 25(96), pp.743-769.

SANCHEZ, L.H.A., SANCHEZ, O.P. \& ALBERTIN, A.L., 2015. Gestão de recursos do EAD: como adequar as tecnologias aos perfis de assimilação. Revista de Administração de Empresas, 55(5), pp.511-526. 